\title{
SENHORIO, PODER SENHORIAL E EXERCÍCIO DA JUSTIÇA NOS COSTUMES DE BEAUVAISIS
}

\section{ANA CATARINA ZEMA DE RESENDE*}

Resumo: O estudo dos direitos de justiça e de polícia na obra de Philippe de Beaumanoir, Costumes de Beauvaisis, foi conduzido a partir do exame dos conceitos de senhorio e de poder senhorial, conceitos fundamentais para compreensão das relações de poder no período medieval. Sob o ângulo da antropologia jurídica, pretendeu-se analisar os direitos de justiça e de polícia dos senhores feudais como estabelecidos nos Costumes de Beauvaisis, para mostrar que no século XIII, quando os conflitos entre senhores cessam, o que passa a ter importância para a afirmação do poder do senhor é o exercício de justiça. Após breve apresentação do autor e da fonte, expõe-se, em um primeiro momento, apontamentos historiográficos sobre a temática do senhorio e do poder senhorial para, em seguida, analisar nos Costumes de Beauvaisis os direitos de justiça e de polícia que são aqueles que dão ao senhor o poder de julgar, de punir, de cobrar taxas e multas e de afirmar seu poder de ban. Finalmente, conclui-se que o exercício da justiça está na base de todos os outros direitos e que é graças ao seu direito de justiça que o senhor vai adquirir o poder necessário para exigir de todos seus súditos os outros direitos.

Palavras-chave: Senhorio. Justiça. Philippe de Beaumanoir.

\section{Seigniorial System, Seigniorial Power and the Exercise of Justice in the Customs of Beauvaisis}

\begin{abstract}
The study of the rights of justice and police in the work of Philippe de Beaumanoir, Customs of Beauvaisis, was conducted considering the concepts of seigniorial system and seigniorial power, which are fundamental for understanding the relations of power in the medieval period. From the perspective of law anthropology, the rights of justice and police of the feudal lords, as established in the Customs of Beauvaisis, was analyzed to show that in the thirteenth century, when conflicts between masters cease, the exercise of justice became important for the affirmation of the power of the lord. After a brief presentation of the author and the source, historiographic notes on the subject of the seigniorial system and the seigniorial power are presented and the rights of justice and police in the Customs of Beauvaisis are analyzed. These rights are the ones that give the Lord the power to judge, to punish, to charge fees and fines and to assert their power to ban. Finally, it is concluded that the exercise of justice is the basis of all other rights and that due to his right to justice, the Lord gains the necessary power to demand the other rights from all their subjects.
\end{abstract}

Keywords: Seigniorial System. Justice. Philippe of Beaumanoir.

\section{Introdução}

O século XIII, como sustentou Jacques Le Goff, representa o apogeu, o zênite, o

\footnotetext{
* Pesquisadora do Grupo de Estudos em Direitos Étnicos Moitará da Faculdade de Direito da Universidade de Brasília. Doutora em História Social pela Universidade de Brasília.
} 
pico da Idade Média. Ele marca a última fase de um período que vai dos arredores do ano 1000 ao começo do século XIV, um período de prosperidade, de crescimento populacional, de expansão das culturas, quando as terras se tornam mais férteis, quando acontece um revigoramento urbano e comercial, quando aparece a máquina, quando se difunde a moeda, quando "escolas e universidades são fundadas, a arte romanogótica desabrocha, as mentalidades afinam-se, os sentimentos interiorizam-se, um humanismo cristão multiforme retorna às fontes do cristianismo, desenvolve-o e aperfeiçoa-o." (Le Goff, 1982, p. 8).

Época de muitos feitos notáveis sem dúvida, mas que conheceu a Inquisição, a intolerância e a violência. Foi uma época marcada pela importância e pela abundância dos conflitos jurídicos, quando justiças e tribunais franceses começaram a se consolidar. O século XIII foi também um período marcado pela sede da expressão escrita. Coletividades, principalmente as urbanas, reclamavam a fixação das normas cujo caráter flutuante havia levado a tantos abusos. Escritores sem missão oficial e simplesmente para a comodidade dos praticiens (operadores do direito) se dedicavam a colocar por escrito os costumes e as normas jurídicas em vigor entre eles. Foi a época do renascimento do direito romano e, com ele, de uma técnica jurídica.

Nesse contexto, insere-se a obra Costumes de Beauvaisis de Philippe de Beaumanoir. ${ }^{1}$ E para realçar sua importância e o significado desse tipo de testemunho, lembramos aqui as palavras de Marc Bloch quando chamou atenção para o fato de que nenhum historiador do feudalismo poderia renunciar "ao socorro do mais admirável analista da sociedade medieval, o cavaleiro, poeta e neto de São Luís, o autor em 1283 dos Costumes de Beauvaisis: Philippe de Beaumanoir" (1994, p. 179).

De fato, trata-se de uma fonte importante para se entender melhor a sociedade do norte da França no século XIII. Por ser um tratado de direito, é uma fonte que documenta com precisão as regras fixadas pelos costumes que diziam respeitos aos direitos e obrigações dos senhores feudais, vassalos, homens livres e servos, particu-

\footnotetext{
${ }^{1}$ A obra Costumes de Beauvaisis usada aqui é a edição de Am. Salmon publicada pelas Edições A. e J. Picard no ano de 1970. Trata-se de uma reimpressão da edição original (primeira publicação de Am. Salmon) de 1899. Essa reimpressão é o resultado de um estudo feito sobre as cópias da obra de Philippe de Beaumanoir que chegaram até nós. Ao total são treze cópias se contadas as que foram feitas no século XVII a partir de manuscritos conservados. De acordo com a edição de Salmon, a obra é dividida em setenta capítulos. Cada capítulo é constituído de vários parágrafos, perfazendo no total, os dois primeiros volumes juntos, 1982 parágrafos.
} 
larmente, para o condado de Clermont de Beauvaisis, antiga região de Beauvaisis, na Picardia. Antes, porém, de abordar o tema central, é importante retomar o debate historiográfico mais recente sobre o conceito de senhorio e seu corolário, o poder senhorial. Conceitos que fazem parte de um grupo maior, caracterizador da sociedade feudal, e que são de grande importância não apenas para a definição do feudalismo, mas também para a compreensão do poder de justiça e de polícia dos senhores feudais em Beauvaisis. Juntamente com a exposição dos conceitos, retomamos aqui alguns pontos sobre a linha de interpretação da antropologia jurídica, linha essa que inspirou a condução desse estudo. Como é sabido, o mérito da abordagem antropológica no estudo da história é quase todo dos medievalistas. Foram eles os primeiros a aproximarem as duas disciplinas, enriquecendo em muito a história em geral e a história da Idade Média em particular. No caso específico da história do direito feudal, a antropologia trouxe uma enorme contribuição para as questões que, até então, eram vistas de uma perspectiva excessivamente jurídica.

O estudo do exercício da justiça na obra de Philippe de Beaumanoir deve contribuir para o entendimento das relações de poder entre os senhores feudais e os homens a eles sujeitos. Essas relações de poder devem ser compreendidas em seu conjunto, considerando-se a complexidade da sociedade feudal, ou seja, serão examinados os direitos de justiça e de polícia dos senhores feudais que recaem não apenas sobre os servos, mas também sobre os homens livres e os nobres. Além disso, é preciso lembrar que o termo "servos" abrange "uma gama mais ou menos rica de dependências" (Barthélemy, 1992, p. 253). Para tanto, foram selecionados alguns direitos do Conde de Clermont de Beauvaisis que caracterizam seu poder de justiça e de polícia com o objetivo de compreender que tipo de poder eles refletiam e como eram definidas as relações do senhor com seus súditos por intermédio desses direitos. Seguindo a linha teórica da antropologia jurídica, a proposta deste trabalho é estudar o exercício da justiça nos Costumes de Beauvaisis enfatizando os processos de interação social em detrimento das estruturas institucionais.

Parte-se, então, do princípio de que o direito está profundamente enraizado no social e no cultural. O direito é uma das formas mais expressivas da organização social e um reflexo fiel do ambiente cultural ou, como dizia Henri Lévy-Bruhl, "o direito é um elemento essencial da vida social" (1955, p. 8). O direito é um sistema de obrigações 
que se impõe a cada momento e a cada situação aos membros do grupo, mas não é o único sistema de obrigações, a moral e a religião, por exemplo, constituem sistemas de obrigações. O direito consiste em um sistema de obrigações ditadas pela coletividade, tem um caráter social e é também a expressão de uma relação de poder. O direito é um conjunto de regras obrigatórias que determinam as relações sociais tais como as representa a vontade coletiva predominante no grupo. É considerado pela sociologia e pela antropologia jurídica o fato social por excelência que, "mais que a religião, mais que a linguagem, mais que a arte, revela a natureza do grupo" (Lévy-Bruhl, 1955, p. 37).

Por isso, para quem quer conhecer uma coletividade, a primeira ordem de documentos que se deve consultar é a das leis ou, mais exatamente, a maneira como suas leis são formuladas e aplicadas. Segundo Lévy-Bruhl:

As regras jurídicas de um povo são o espelho de suas aspirações e da relação de forças que estão em jogo. É o direito que expressa de forma mais fiel as reações do corpo social, na medida em que sua função própria é fixar as relações entre seus membros $(1955$, p. 37).

Baseados na concepção de direito de Lévy-Bruhl e conscientes da necessidade de se repensar nosso próprio sistema jurídico, antropólogos desenvolveram a linha teórica da antropologia jurídica. Pode-se definir a antropologia jurídica como sendo a “disciplina que, pela análise dos discursos (orais e escritos), práticas e representações, estuda os processos de jurisdicização próprios a cada sociedade e procura descobrir as lógicas que os comandam" (Rouland, 1990, p. 7). Entendendo-se por "jurisdicização" o processo de construção do direito em cada sociedade, que leva em conta aspectos que o historiador do direito tradicional não enxergava como, por exemplo, tudo que diz respeito à produção de valores no direito, à moralidade, aos sentimentos em relação ao outro, à natureza, a Deus, etc., enfim, considerando fatores que estão por trás da constituição de um sistema jurídico.

Desse modo, sob o ângulo da antropologia jurídica, o estudo dos direitos de justiça e de polícia dos senhores feudais nos Costumes de Beauvaisis como proposto aqui não busca apenas conhecer o conteúdo das prescrições jurídicas e de suas sanções, mas procura compreender quais os valores que a sociedade em foco privilegia 
quando define o conteúdo de seus direitos e como esses direitos expressam as relações de poder em jogo na dinâmica social.

\section{Sobre a obra e o autor}

A obra Costumes de Beauvaisis ${ }^{2}$ é um tratado de direito consuetudinário do século XIII que tornou célebre o nome de Philippe de Beaumanoir. Esse livro constitui uma das grandes obras do século XIII, sendo qualificado por muitos historiadores principalmente os que se ocupam do direito e das instituições, como Jacques Ellul (2013), François Olivier-Martin (1992), Jean-François Lemarignier (1970) e G. Lepointe (1937) - como a compilação mais completa, mais bem redigida e mais representativa do direito consuetudinário do século XIII. Para fazer essas afirmações, esses historiadores se basearam na comparação deste coutumier com os outros coutumiers da mesma época: Les établissements de Saint Louis, Conseil à un ami, Le livre de la jostice et de plet e Grand coutumier de Normandie, chegando ao consenso que o coutumier fundamental é o de Philippe de Beaumanoir.

Beaumanoir nasceu em Lorris, depois do ano de 1247. Viveu durante os reinados de São Luís, Filipe II, o Audaz, e veio a falecer em 1296, durante o reinado de Filipe, o Belo. Ele teria escrito dois grandes romances: Manekine e Jehan de Dammartin et Blonde d'Oxford, além de muitos poemas que, segundo especialistas são repletos de graça, calor e de desembaraço na expressão escrita. Philippe de Beaumanoir é o segundo filho de um nobre, cavaleiro e bailio ${ }^{3}$ de Gâtinais e de Artois, Philippe de Rémi. Beaumanoir serviu ao Conde Robert d'Artois, irmão de Luís IX e foi nomeado bailio do condado de Clermont em Beauvaisis no dia 11 de maio de 1279, onde permaneceu até

\footnotetext{
${ }^{2}$ Embora a maior parte das obras daquele momento tenham sido redigidas em latim, o tratado em questão está em francês medieval e não foi, até os dias de hoje, traduzido para o francês moderno ou para qualquer outra língua de origem latina. Na verdade, existe uma tradução desta obra feita em 1971 pelo professor Hiroshi Hanawa da Faculdade de Direito de Kobi em língua japonesa (Hubrecht, 1974, p. 2). Trata-se, no entanto, de uma fonte que assume caráter mais amplo, pois ultrapassa os limites do território do condado de Clermont em Beauvaisis e se estende a condados vizinhos, onde vai buscar as bases para a descrição dos costumes da região. O quadro do condado de Clermont estendese até onde a justiça funcionava, ou seja, abrange outras cidades, outros senhorios, outros condados que obedeciam basicamente às mesmas regras.

30 bailio, antes de 1185, era um agente especial do rei ou de um senhor, responsável por diversas tarefas. A partir desta data, é um funcionário da corte do rei que, temporariamente, é encarregado de funções essencialmente judiciárias e de controlar o trabalho dos prebostes responsáveis pela manutenção da ordem e pela polícia.
} 
a época em que expirava seu terceiro exercício regulamentar, ou seja, até 7 de maio de 1282. ${ }^{4}$ Os Costumes de Beauvaisis foram redigidos durante esse período e sabe-se que ele concluiu sua obra no ano de $1283 .^{5}$

Os Costumes de Beauvaisis, ao contrário da maior parte dos coutumiers da época, não é uma obra anônima. Beaumanoir assina e data o tratado no final do último capítulo, o que não era nada comum para a época. Mas ele só se identifica para não correr o risco de ser contestado por causa de sua pouca idade ou de suas funções (§ 1982). Beaumanoir tinha apenas trinta anos de idade quando escreveu o tratado. De qualquer maneira, a espessura de seu trabalho, sua lucidez e o seu profundo conhecimento do direito impressionam ainda hoje aqueles que sobre sua obra se debruçam.

No parágrafo primeiro do prólogo, ele esclarece o espírito que o animava quando principiou a escrita de sua obra. Ele pretendia escrever um livro que ensinasse como se defenderiam aqueles que, "por azar e malfeito", se envolvessem em processo judiciário, "utilizando-se do conhecimento do direito e dos costumes do condado de Clermont em Beauvaisis", direito e costumes que ele mesmo pretendia "fazer respeitar em nome do conde e de seu conselho em vista de uma boa administração e para a paz de todos" (§ 1).

Beaumanoir precisa também quais foram suas fontes: a jurisprudência, os hábitos e os costumes, reconhecidos desde muito tempo, mas que ele desejava registrar por escrito para que, desde então, fossem fixados (§ 6 e 7). Sua intenção de gravar por escrito esses hábitos e costumes pressupõe uma preocupação com uma questão importante para o mundo do direito nessa época: a influência do direito romano no pensamento jurídico e a consolidação da escrita em detrimento de um direito, ainda em muitas regiões, baseado na transmissão oral.

Beaumanoir acrescenta que, nos casos duvidosos e perigosos, ele recorreu à jurisprudência dos senhorios vizinhos e que, quando isso não funcionou, ele recorreu então ao "direito comum" ${ }^{6}$ do reino. Ele abre assim um espaço maior para seu campo

\footnotetext{
${ }^{4}$ Essas datas são conhecidas, sobretudo, graças à obra de Bordier (H.L.), Philippe de Rémi, sire de Beaumanoir, 1246-1296, de 1869-1873, que é citado por Am. Salmon na sua introdução.

5 "Ici fine Phelippes de Beaumanoir son libre lequel il fist des coustumes de Beauvoisins en l'an de I'incarnation de Nostre Seigneur mil.cc.lxxx. et iii" (Beaumanoir, 1970, p. 502).

${ }^{6}$ Entre os eruditos persiste uma pendência sobre o que Beaumanoir entende por "direito comum". De um lado, Salmon afirma que esta expressão evoca as leis aplicáveis a todo reino e, de outro, Georges Hubrecht, o grande historiador do direito que fez o comentário histórico e jurídico do coutumier de
} 
de pesquisa recorrendo aos costumes da vizinhança e ao direito comum do reino da França e isso no momento mesmo em que se sente forte a tendência em estabelecer uma certa comunidade dos costumes da França real. Percebe-se que ele procura ultrapassar os casos particulares para definir regras gerais, ainda mais quando se sabe que, ao contrário dos outros coutumiers, o nome das partes envolvidas, dos juízes e as datas não o interessam.

Trata-se de uma fonte complexa de onde se pode extrair muitas informações para se conhecer a sociedade do norte da França e a justiça do século XIII e onde se pode encontrar embasamento preciso sobre as regras fixadas para os direitos de justiça e de polícia dos senhores feudais que nos ajudam a compreender a natureza e o funcionamento do senhorio e do poder senhorial.

\section{Senhorio e poder senhorial no debate historiográfico contemporâneo}

Um dos temas fundamentais para discutir as relações de poder na Idade Média é o senhorio e o poder senhorial a ele associado. Tema incontornável não apenas porque é obrigatório nos programas das disciplinas de História Medieval na França, mas essencialmente porque permite-nos compreender o mundo que surge logo após a Revolução Francesa quando, finalmente, o senhorio desaparece na França. O senhorio é a célula primeira da vida cotidiana entre os séculos X e XVIII, inclusive na sua especificidade urbana ainda que minoritária. Trata-se de um sistema social que além de determinar as relações sociais, econômicas e jurídicas entre os dominados e os dominadores durante muitos séculos, determinou também as mentalidades, mantido por uma ideologia que o legitimou e que serviu, evidentemente, à classe dominante com o apoio do clero para justificar esse sistema social. Na Europa Ocidental, esse sistema perdurou até a Revolução Francesa. Mas se considerarmos que a servidão é um dos elementos que participa da definição do sistema senhorial, foi preciso esperar até meados do século XIX para que fosse abolido na Europa Central e Oriental e, até 1917, para que fosse abolido na Rússia.

De acordo com Jérôme Baschet, desde a obra clássica de Georges Duby, Economia rural e a vida no campo no Ocidente Medieval (1977), sabemos que a partir do 
século IX os laços de fidelidade que mantinham as relações entre senhores e rei vão se tornando mais frágeis e as entidades territoriais cada vez mais autônomas nas mãos da aristocracia local. É o tempo dos "principados", época em que os senhores de terra confundem "aquilo que concerne seu próprio poder, militar e fundiário com a autoridade pública, que no passado era conferida pelo imperador ou rei" (Baschet, 2006, p. 126).

A terra é fonte de renda e de prestígio para o senhor que a possui. Os feudos são as terras concedidas por um senhor a seus vassalos e o senhorio se funda sobre a posse da terra e sobre os direitos que ela implica. Como explica Baschet, o mesmo processo que levou à "patrimonialização da função do conde", quando este assumiu a defesa militar e o exercício da justiça e que levou à formação de comandos autônomos e transmitidos hereditariamente, foi se repetindo depois em um nível inferior (2006, p. 126). Devemos considerar, no entanto, a grande variedade regional em que se apresenta o senhorio e os ritmos diferentes de acordo com os quais esse processo se deu:

Em ritmos diferentes e de acordo com modalidades variáveis segundo as regiões - sem falar de uma infinidade de situações intermediárias, uma parte importante do poder de comando inscreve-se, doravante no quadro dos vice-condados e das "castelanias" que, por sua vez, encampam o exercício da justiça e o direito de construir castelos, antes prerrogativas da autoridade real e, depois da autoridade condal. Por fim, senhorios de extensão ainda mais reduzidas tornam-se, no fim do século XI e durante o século XII, um dos quadros elementares do poder sobre os homens (Baschet, 2006, p. 126).

A querela entre os historiadores para saber quando esse sistema de enquadramento dos homens começou a existir deve ser, por isso, relativizada; sobretudo, se considerarmos as desigualdades geográficas das fontes que, muitas vezes, nos impedem de discernir, se os poderes são, na sua origem, fundiários ou públicos (Fossier, 1995, p. 18).

O senhorio representa o elemento característico de um regime social que, convencionalmente, foi chamado de feudalidade. O senhorio é "um território razoavelmente grande e disperso em que o senhor é, ao mesmo tempo, proprietário e soberano, exercendo um largo poder de comando" (Olivier-Martin, 1992, p. 126).

Para François Olivier-Martin, assim como para Norbert Elias (1993), o alvorecer 
da feudalidade está marcado por dois fenômenos concomitantes: o enfraquecimento do poder real e a autonomia do senhorio. O processo é conhecido: os grandes funcionários carolíngios - duques, marqueses, condes e viscondes - apossaram-se das funções públicas que lhes haviam sido concedidas pelo rei; os grandes proprietários tornam-se senhores em suas terras, daí as guerras privadas do século $X$, a multiplicação dos castelos, a impotência da realeza, etc.

Marie-Thérèse Lorcin levanta um aspecto não menos importante. Para ela, o senhorio surge como "uma resposta a uma necessidade de se aproximar os centros do poder administrativo, judiciário e militar dos habitantes, em uma época de insegurança, e na qual as comunicações são lentas e difíceis" (1985, p. 91).

Para Robert Fossier, o senhorio é, na ausência de um poder público solidamente organizado, uma "forma de enquadramento dos homens, social, política e economicamente, que estabelece entre seus membros um contrato, em geral tácito, de ajuda e de proteção sinalagmática [...]" (1995, p. 15).

O senhorio nasce da parcelarização do poder. Um dos fatores mais característicos do feudalismo é a parcelarização da soberania, resultado da decadência do poder real que foi incapaz de conter os ataques do exterior. As pessoas precisavam ser protegidas e rapidamente o poder real foi parcelado passando a defesa para as mãos dos príncipes locais. Esse processo de parcelarização continuou e, aos poucos, os grandes principados foram se desintegrando. Os senhores de média linhagem, primeiro os condes e depois os comandantes das fortalezas, obtiveram a sua independência dos príncipes. O monarca passa a ser uma simples figura decorativa, ele é o suserano feudal de seus vassalos e não um soberano supremo acima de seus súditos. Seus recursos econômicos provinham dos seus domínios pessoais e, aos seus vassalos, pedia contribuições essencialmente de ordem militar. O monarca "não tinha acesso político direto ao conjunto da população, pois a jurisdição sobre ela era exercida por intermédio de inúmeras sub-instâncias feudais" (Anderson, 1982, p. 168).

De qualquer maneira, é possível falar em senhorio quando se reconhece a existência de um senhor e os seus praticando um tipo de vida particular, vivendo essencialmente do produto do trabalho dos outros e, a seu lado, esses outros dependendo dele sob diversos aspectos. Por trás do poder senhorial estão, de acordo com Robert Fossier, o peso econômico, o poder, ou seja, os meios de exercer controle sobre os 
outros, e o prestígio por pertencer a um grupo social excepcional (1995, p. 14).

Para Philippe Contamine, o senhorio implica primeiramente uma ideia de dominação. Ele analisa os diversos empregos que o homem medieval dava aos termos "senhor" e "senhorio" e mostra que o aspecto principal que sobressai dessas observações é o caráter de dominação:

Especialmente no final da Idade Média, o termo senhorio implica antes de mais nada a ideia de dominação. Deus é nosso senhor. O rei exerce seu senhorio sobre o reino da França, seus habitantes e seus súditos. Fala-se do senhorio de Veneza, do senhorio de Florença, do senhorio do duque da Bretanha ou do duque de Bourbon. Textos nos mostram que o marido deve ter o senhorio sobre sua esposa [...] (1995, p. 26).

Como explicar essa dominação? Quais são os elementos sobre os quais repousam o senhorio e o poder senhorial? Para Robert Fossier, esse poder é primeiro de ordem social, e mesmo, de ordem moral, espiritual e carismático. O senhor e seus pares são socialmente diferentes dos outros. São nobilis, ou seja, "dignos de serem conhecidos", de acordo com a etimologia da palavra (1995, p.19). O senhor é diferente por seu modo de vida: seu código moral é "tomar para distribuir, exigir para gastar", por isso ele tem que ser generoso, mas de acordo com as medidas pregadas pela Igreja que sempre oscilou entre o orgulho e a avareza. Ele é diferente por causa da sua aparência exterior e de seus costumes: ele come muito, dá esmola, a eles são reservados alimentos raros, o vinho forte, roupas de preço, uso do vermelho. Sua moradia é diferente da dos outros. O castelo domina as casas menores pelo tamanho e pela qualidade da construção, mas também por ser uma edificação que se encontra acima de todas as outras (Fossier, 1995, p. 19).

O nome de sua família o distingue do vulgar. Ele sabe cavalgar e essa é uma manifestação exclusiva da nobreza. Ele tem direito de albergue ou direito de gîte que Ihe permite se alojar na casa de seus súditos em certas ocasiões, o que significa também estabelecer contatos e, por que não, laços de afeição (Fossier, 1995, p. 20).

Seu poder é também de ordem econômica, e esse campo de estudo foi, sem dúvida, o mais amplamente estudado pelos historiadores. Ele é senhor da terra e do dinheiro. A Igreja, nesse caso, ocupa o lugar mais importante e isso, provavelmente, porque os arquivos estão repletos de sinais de sua riqueza. Com o tempo grandes pro- 
dutores rivalizam com o senhor, mas até o século XIII é ele que tem condições de se equipar, adquirir máquinas, sementes e ferramentas de todos os tipos que o progresso da técnica colocou à sua disposição.

Essa dominação, quase de tipo técnico, conforme Robert Fossier, está na origem da constituição daquilo que foi chamado de "renda senhorial". No entanto, como estudos recentes mostraram, os arrendamentos recebidos em espécie ou in natura sobre as terras, não compõem o essencial da renda senhorial; talvez $5 \%$ do total, porque o grosso vinha mesma da transmissão hereditária (1995, p. 20). Os serviços exigidos são rapidamente substituídos por taxas e também não são muito rentáveis. É, então, sobretudo o exercício da justiça, as multas e os costumes que garantem ao senhor uma parte essencial de sua renda e seu poder.

Enfim, sobre o plano político ele tem a mão forte, mas não quer dizer que é o tirano da aldeia. Isso seria esquecer que o peso de sua mão corresponde à proteção que é dada em contrapartida. O bellator não é esse terrorista que alguns historiadores estigmatizaram. No esquema das três ordens ele aparece como o mais ameaçado, a mais vulnerável das criaturas de Deus, porque é exatamente sua atividade de dominação que o expõe, mais que os outros, aos riscos danação (Fossier, 1995, p. 21).

A hierarquização dos senhorios acompanha o escalonamento dos títulos de nobreza: principados, ducados, marquesados, condados, viscondados e, mais tarde, as baronias. De acordo com Olivier-Martin (1992), esta última categoria corresponderia aos grandes senhorios, à qual se junta ainda o senhorio eclesiástico. O verdadeiro senhorio típico é a castelania que tem como centro um castelo do qual dependem os feudos necessários à manutenção normal de sua guarnição. O castelo concentra o poder jurídico, os mantimentos, o serviço militar, etc.

Robert Fossier e a maioria dos medievalistas contemporâneos descartam a tese de uma organização anárquica da sociedade feudal. Para ele, não há, para a época em questão, outro tipo de organização que enquadraria melhor os homens. Ele chama a atenção também para a diversidade regional.

Olivier-Martin também rejeita a teoria de uma feudalidade anárquica. Assim, ao contrário da anarquia, a feudalidade revela-se como uma grande tentativa de organização social que se arranja da melhor forma possível para suprir as deficiências do Estado. No quadro do senhorio, diz ele, o esforço de organização é nítido: 
Os senhores não parecem ter abusado de sua situação privilegiada sobre os habitantes de seu senhorio. Eles precisavam deles para construir, consertar, vigiar o castelo; uma solidariedade elementar os unia para fazer face aos perigos de uma era de violência (1992, p. 129).

No entanto, por mais cooperativa que pareça a organização social do senhorio, não podemos subestimar o peso da autoridade senhorial. Por trás dessa autoridade situa-se o poder, ou seja, os meios de exercer formas de controle sobre os outros. Poder que se apresenta sob diversas formas, no plano econômico, político, social, moral, etc., escondendo dois fatores fundamentais: o econômico, pois é o senhor feudal que tem o domínio sobre as terras, e o social, na medida em que guarda uma preeminência social, moral e afetiva, pois tem o prestígio por pertencer a um grupo social excepcional que provoca o afeto, o respeito, o temor e a submissão daqueles que estão nos degraus abaixo.

Não se rejeita a tese de Olivier-Martin sobre a cooperação e a solidariedade que existe entre o senhor e seus súditos. Acredita-se que o poder senhorial deve ser definido a partir dos três pilares em que se assenta: o da cooperação e solidariedade, o da dominação e, um terceiro que permite o equilíbrio, o da exploração.

Georges Duby (1977) trata desse aspecto no seu livro sobre economia rural e a vida no campo. Segundo ele, a exploração aparece primeiramente no trabalho. Era graças à importância da quantidade de mão de obra em seu domínio que o senhor feudal podia esgotar a exploração em seu território. O trabalho dos servos constituía, nos primeiros anos da época feudal, a principal fonte de riqueza do senhor.

A partir do século XII, a exploração muda um pouco de figura, ou melhor, ganha uma nova forma. Duby defende a tese de que, a partir desse momento, a maior parte da fortuna senhorial vinha do exercício da justiça. Havia muito tempo que os servos estavam sujeitos à correção de seu senhor e quando as instituições públicas responsáveis pelo exercício da justiça se enfraqueceram, os senhores locais passaram a exigir do senhor regional o direito de fazer a justiça e de punir seus homens (1977, p. 79).

As punições poderiam assumir a forma de pagamento em espécie e, segundo Duby, o senhor feudal aproveitava o máximo desse direito, aumentando assim sua riqueza. Quase sempre as multas cobradas ultrapassavam o valor de que dispunha o servo, então o senhor tirava de sua casa o que podia (1977, p. 82). No capítulo XXX dos 
Costumes de Beauvaisis, Beaumanoir cita vários exemplos de cobranças de multas de acordo com o tipo de crime cometido e outras formas que possibilitavam o aumento da fortuna senhorial, como veremos logo a seguir.

O poder senhorial é, em geral, definido em associação aos direitos que o senhor feudal possuía. Os direitos senhoriais, fixados pelo costume, não são apenas de ordem jurídica, são também de ordem militar, fiscal, econômica. São esses direitos que vão determinar as obrigações às quais deveriam submeter-se os súditos.

Os direitos senhoriais visam a todos os súditos do senhor: os servos, os hommes de poésté (do latim homines de postestate, que quer dizer homens sob o seu poder) e os vassalos. É importante sublinhar que o termo servo assume uma conotação bastante diferente no século XIII daquela de sua origem na Alta Idade Média, pois o século XIII é o auge das cartas jurídicas de libertação e muitos homens livres passam a figurar nos domínios do senhor.

Beaumanoir, no capítulo XLV, define a condição de servos. Abaixo do clero, existem em Beauvaisis três estados: os nobres, os homens livres e os não livres que são os servos. No entanto, deve ser registrado que quando a expressão hommes de poés$t e^{7}$ aparece no texto de Philippe de Beaumanoir, ele está se referindo aos homens livres, aos vilãos, o que permite concluir que, em Clermont de Beauvaisis, os homens livres ainda estavam sujeitos a muitos direitos senhoriais.

Lemarignier (1970) classifica os direitos senhoriais em: jurídicos, militares, fiscais e econômicos. Os direitos de ordem militar são aqueles que o senhor exige para guarda e defesa do castelo, participação em guerras, mas também serviços ou corveias de construção ou de reparação do castelo. Os de ordem fiscal são as talhas e as corveias e outros tipos de tributos pagos in natura ou em espécie. Os direitos de ordem jurídica são, sobretudo, aqueles que dão o poder de julgamento e punição. Os de ordem econômica são tanto os que regulam os meios de comunicação - ou seja, aqueles que se ocupam do trânsito das pessoas, das feiras, dos mercados e dos meios de troca quanto as banalidades por meio das quais o senhor cobrava pagamento in natura pelo uso dos meios de produção que ele monopolizava (1970, p. 117).

Georges Duby (1977) propõe um outro tipo de classificação. Ele classifica os di-

\footnotetext{
${ }^{7}$ A expressão aparece nos manuscritos de Beaumanoir como hommes de poosté - derivação ortográfica comum de região para região.
} 
reitos de acordo com sua origem, que remonta ao ano mil. Os direitos senhoriais derivam do poder de ban (comando) que os senhores adquirem ou tomam por volta do ano mil. Na origem desse poder estão a justiça pública, as requisições militares, as corveias, as banalidades e as talhas que aparecem em um momento posterior aos outros. Essa classificação apresenta um inconveniente que é o de ser muito sintética, pois a cada origem corresponderia uma gama enorme de direitos.

Pierre Charbonnier (1995) apresenta uma classificação dos direitos senhoriais que parece, até agora, a mais exata. Primeiramente, sete grandes grupos: 1) locações, que enquadram os direitos relativos à propriedade territorial do senhor; 2) mutações, que se referem aos direitos de mudança tanto de bens como das pessoas, o formariage e a mainmorte fazem parte desse grupo; 3) monopólios, de todos os tipos, ligados às técnicas, aos animais de reprodução, comerciais e os honoríficos (caça, pombario); 4) justiça e polícia, direitos sobre tudo que diz respeito à manutenção da ordem; 5) trocas, todos os direitos relacionados com a atividade cambial e seus elementos constitutivos, como a moeda, as medidas, o peso, as feiras, os pedágios; 6) guerra e defesa, direitos sobre o serviço militar, aprovisionamento para a guerra ou imposto de paz e defesa do castelo, corveias de manutenção e 7) tributos propriamente ditos, talhas anuais, corveias pessoais proporcionais aos feudos e à riqueza deles, direito de gîte (abrigo) (1995, pp. 139-151).

\section{Direitos de justiça e de polícia nos Costumes de Beauvaisis}

O direito de justiça, seja esta alta ou baixa, é para o senhor a base de todos os seus outros poderes. Executar a justiça não significa apenas corrigir, punir e tomar decisões com a convicção de ser obedecido, mas também manter a paz e, principalmente, recolher as rendas. De acordo com François Olivier-Martin (1992, p. 139),

o direito de justiça conhece prerrogativas muito extensas, vizinhas das da soberania. Ele não confere ao senhor apenas o direito de julgar os processos, mas também o de tomar, dado o caso, medidas gerais para o bem comum do senhorio. Não mais do que o próprio rei, o senhor não pode, em princípio, desobedecer ou causar prejuízo aos costumes do senhorio, mas ele pode promulgar novos bans (poderes) ou novos estabelecimentos aplicáveis por toda sua terra e cuja violação seria sancionada com multa. 
Observa-se que a divisão territorial acompanhou a privatização da justiça ou, como explica Robert Boutruche (1970, p. 126-127), "os fourches (forcados) e as cruzes dispostas no interior e nos limites dos senhorios políticos são o sinal das justiças". Cada senhor reivindica o conhecimento dos delitos cometidos por seus subordinados e o conhecimento das causas nas quais estão implicados os habitantes de sua terra. A justiça é o símbolo por excelência da autoridade.

Os direitos de justiça e de polícia são principalmente aqueles que permitem ao senhor julgar, punir seus homens e afirmar seu poder de ban. Esses são também os direitos que garantem a manutenção da ordem na área de dominação do senhor.

O exercício de seu poder de justiça permite ao conde de Beauvaisis, por exemplo, cobrar uma multa por profit de défaut (\$60), caso em que uma pessoa é citada para comparecer em justiça e não pode ir no dia da convocação. Essa pessoa teria que ter feito um contremand ou uma essoine. O contremand é uma declaração feita no nome da parte citada dizendo que ela só poderá comparecer dentro de quinze dias. A essoine é uma desculpa que permite não se apresentar na data da convocação. A essoine é aceita somente uma vez, ou seja, ela não pode ser repetida; ela deve ser leal e afirmada sob a lei do juramento se a corte assim o exigir. Nas palavras de Beaumanoir, "[...] et bien se gart qu'il ait loial essoine, car il convenra jurer son essoine en court se li sires veut, et, s'il ne le veut jurer, il sera tournés en défaute" ${ }^{8}(\S 60)$, ou seja, se não apresentar leal essoine, a pessoa convocada a comparecer em justiça sofrerá as consequências de seu não comparecimento, qual seja, pagará uma multa conhecida por profit de défaut.

Se em um processo o pleiteante não se apresentar para sustentar sua queixa contra outrem, ele deverá ao senhor uma multa por ter, de alguma forma, incomodado a corte inutilmente. Se é o defensor que não comparece, ele perde imediatamente o processo; perde também a posse do bem que lhe é reclamado quando este for o caso. Se as duas partes não comparecem, o senhor justiceiro coloca o defensor em estado de défaut, ou seja, de não comparecimento até que ele saiba quem é o verdadeiro culpado e possa cobrar a multa daquele que cometeu o delito (§ 85).

\footnotetext{
8 “[...] e ele cuidará que seja leal essoine (pedido de desculpas), pois ele deverá jurar sua essoine diante da corte se assim o senhor o desejar, e, se ele não quiser prestar juramento, ele será considerado culpado." (§ 60). (Tradução da autora).
} 
O senhor, que deve guardar e proteger as estradas e as pessoas que nelas circulam, tem também a "justiça do caminho" e, para isso, basta que o caminho passe pela terra sobre a qual o senhor tem a justiça. Beaumanoir explica que,

de direito comum, todo caminho, seja o de dezesseis pés, de trinta e dois pés ou de sessenta e quatro pés, são e pertencem, em todas as coisas, ao senhor que possui a baronia, estejam estes caminhos nas suas terras ou nas terras dos seus súditos e é deles toda a justiça e o senhorio dos caminhos $(\S 721) .^{9}$

A justiça desses caminhos é, particularmente, proveitosa para o senhor por causa da competência das infrações que neles são cometidas. Por exemplo, no caso onde a largura das estradas não é respeitada, as pessoas que moram nas bordas dessas estradas podem ser castigadas devendo pagar uma multa, a menos que a ausência de demarcações não permita chegar a uma conclusão sobre a má-fé dos moradores ribeirinhos (§ $723-726)$.

Qualquer movimentação que resulte em deterioração, estrago, perturbação ou desordem e, também a construção de muros, fossos ou edificações, ou mesmo a retirada de terra estragando o caminho, é considerada crime sujeito a uma multa, sendo os responsáveis por tais atos obrigados a refazerem o caminho para deixá-lo exatamente como era antes. Também é tido como um grave delito o deslocamento de mar$\cos (\S 850)$ que é unido como uma infração de voirie (referente à conservação das estradas). A multa por infração de voirie nos caminhos públicos era de sessenta sous para os vilãos e de sessenta libres para os nobres (§ 727).

O costume permitia ainda ao senhor exigir de seus súditos encargos para a manutenção das estradas e isso durante um período de até três anos, pois se este prazo fosse ultrapassado seria um novo costume que exigia uma autorização do rei (§ 731). A parte das despesas que cada um deveria pagar era determinada de acordo com seu avenant, ou seja, de acordo com o que produzia na terra, esta estimativa era feita pelo serment de bonnes gens, pessoas escolhidas pelo senhor e sob o seu controle (§ 732).

Os objetos perdidos e qualquer coisa que fosse encontrada nas estradas do se-

\footnotetext{
9 "De droit commun tuit li chemin, meismement cil de.XVI. piés, de .XXXII. piés, sont et apartienent en toutes choses au seigneur de la terre qui tient en baronie, soient li chemin par mi leur demaine ou par mi le demaine de leur sougiès, et est toute la justice et la seignourie des chemins leur." (§ 721).
} 
nhorio deviam ser entregues à alta justiça do lugar. Se apossar de um objeto encontrado em um caminho era considerado uma forma de furto e o crime era condenado como tal. Se ninguém reclamasse o objeto encontrado provando que este the pertencia, o objeto permanecia com o senhor a título de espólio (epave), ou seja, sem dono. Aquele que não agisse de tal maneira, corria o risco de ter que pagar uma multa, cujo montante corresponderia ao valor do objeto encontrado e não declarado (§ 738).

As punições podiam ser exigidas sob a forma de pagamento em espécie e o senhor tirava disso o máximo proveito, aumentando assim sua fortuna. De acordo com Duby, algumas vezes as multas impostas ultrapassavam largamente o valor de que dispunha o servo, nesse caso, o senhor podia entrar em sua casa e retirar dali o que quisesse $(1977$, p. 82).

No capítulo XXX do coutumier, Beaumanoir cita diversas situações de recolhimento de multas por crimes cometidos. Os crimes mais graves, o homicídio, o assassinato, a traição e o estupro, eram condenados com a pena máxima, a pena de morte. Os outros crimes menos graves eram sancionados com multas ou confiscações de bens. A sanção por crimes menos graves como, por exemplo, crimes que causassem um leve ferimento, consistia em uma multa cujo valor variava de acordo com a situação social daquele que cometeu o crime, com o lugar onde o crime ocorreu e com o costume local aplicável. Se o culpado fosse um vilão, a multa para o crime descrito logo acima seria de cinco deniers; se se tratasse de um nobre, a multa seria de dez sous (§ 839). Se os golpes tivessem sido dados no mercado onde havia a presença de outras pessoas, a multa aumentaria para sessenta sous se o criminoso fosse um vilão e para sessenta libres, se o crime fosse cometido por um nobre (§ 839). Neste caso preciso, o valor da multa aumentava consideravelmente porque o mercado era uma área sob a proteção do conde, a agressão corresponderia então a uma quebra de proteção.

No caso de crimes com ferimentos graves, o culpado permanecia preso até o momento em que a vítima estivesse fora do risco de perder a vida. Se a vítima viesse a falecer, a sanção era a mesma do homicídio, a pena máxima. Se a vítima sobrevivesse, o culpado deveria pagar uma multa de sessenta sous se vilão e, sessenta libres, se nobre (§ 840).

Podemos encontrar ainda no coutumier de Beaumanoir várias situações que permitiam ao senhor tomar posse dos bens de seus súditos. Beaumanoir cita o exem- 
plo de uma situação que permitia ao senhor se apossar dos bens daqueles que se encontrassem sob julgamento por um crime (§ 1534), ou ainda, o senhor podia dispor dos bens daqueles que não obedecessem às suas ordens de trégua ou de assecuratio que consistia em uma promessa feita diante de um juiz de não se envolver em casos de "violência recíproca" ou "guerras privadas" (§ 1573).

O coutumier descreve outros tipos de delitos que eram sancionados com a multa de sessenta sous para os vilãos e de sessenta libres para os nobres. É o caso dos insultos, das injúrias e das ofensas feitas diante de um preboste ou de um sargento (§ 847), ou diante de um juiz ( $\$ 845$ ). A resistência ao senhor era também um crime castigado severamente com esta "pesada" multa (§ 876) e, ainda, o fato de espoliar alguém que estivesse sob a saisine do senhor, ou seja, sob sua posse (§ 853).

Quando houvesse uma contravenção às ordens do senhor como, por exemplo, se o senhor proibisse o jogo de dados ou o porte de armas como o arco ou a faca com ponta, aquele que não obedecesse não seria preso, mas deveria pagar uma multa de cinco sous se vilão e de dez sous se nobre (§ 857). Também aquele que fosse pego na floresta do senhor cortando lenha ou nos campos do senhor apanhando trigo deveria pagar igualmente uma multa de cinco sous, se vilão, e de dez sous, se nobre (§ 860).

Aqueles que conspirassem ou conjurassem contra o senhor ou contra o bem comum eram severamente castigados. Beaumanoir cita dois casos: o primeiro é o de um acordo entre mercadores ou artesãos visando aumentar seus preços por sua própria conta sem a autorização do senhor, se o senhor descobrisse esse tipo de conjuração, o criminoso seria castigado com uma longa pena de prisão e com uma multa de sessenta sous para cada uma das pessoas envolvidas na trama ( $(884)$. O segundo caso é o de uma aliança feita entre cidades que se levantassem e se revoltassem contra o senhor, caso o senhor viesse a perceber que tal aliança estaria sendo feita, ele deveria prender os participantes, enforcar os organizadores, condenar a uma longa prisão os outros e confiscar os bens deles todos por terem traído seu senhor (§ 885).

Havia ainda infrações consideradas como muito graves e que eram sancionadas arbitrariamente pelo senhor. É o caso, por exemplo, da fuga da prisão quando a multa a ser cobrada ficava a critério do senhor ( $§ 848)$. Beaumanoir acrescenta que ele nunca viu nenhum senhor pedir uma multa superior a sessenta sous. Também o encobrimento dos banidos era um crime punido segundo a vontade do senhor: "Aquele que rece- 
be um banido em sua casa, (...) estará sujeito a uma multa a critério do senhor, seja ele nobre ou vilão" (§ 859). Em caso de falso testemunho, o coutumier estabelecia que "aquele que prestar falso testemunho e for descoberto passará longa data em prisão e será colocado sobre a eschiele (pelourinho) diante do povo, além de pagar uma multa a critério do senhor" (§ 868).

Esses exemplos retirados do tratado de direito consuetudinário de Philippe de Beaumanoir, entre tantos outros, nos permitem perceber alguns traços específicos do senhorio e do poder senhorial em Beauvaisis. Confirmam a superioridade do senhor sobre seus súditos: vassalos, homens livres e servos; confirmam as hierarquias sociais; e mostram todo vigor das prerrogativas do senhor feudal em pleno século XIII.

\section{Considerações finais}

A obra Coutumes de Beauvaisis de Philippe de Beaumanoir é uma das principais obras para o conhecimento do direito consuetudinário francês da segunda metade do século XIII, sendo os demais coutumiers do século XIII, pela forma e pelo conteúdo, menos ricos e menos elaborados. Trata-se, sem dúvida, de uma fonte histórica do século XIII extremamente rica, com uma quantidade enorme de informações não apenas sobre os aspectos jurídicos do momento histórico, mas também informações minuciosas sobre o condado de Clermont em Beauvaisis com um olhar atento à vida social e às questões políticas.

O coutumier escrito por Philippe de Beaumanoir suscitou principalmente o interesse dos historiadores do direito que fizeram muitos estudos de detalhes consagrados a alguns capítulos ou a algumas instituições, a maior parte desses estudos sendo dissertações de mestrado e teses de doutorado que permanecem pouco conhecidas e que, quase sempre, não dão muita importância aos aspectos históricos e sociais da obra.

A historiografia tradicional do direito determinou alguns princípios definidores da justiça e do direito na Idade Média. Sobreviveu até pouco tempo, por exemplo, a ideia de que não havia na Idade Média um direito estabelecido capaz de resolver os conflitos e os casos de violência no interior da sociedade, o que confirmava a tese de uma sociedade anárquica e bárbara. Os historiadores do direito, por causa da influên- 
cia epistemológica de suas épocas, quase sempre procuraram encontrar na Idade Média um modelo primitivo da justiça atual fazendo uma espécie de decalque primitivo do nosso próprio sistema jurídico. Com o auxílio da antropologia jurídica, os novos historiadores do direito desmontaram as evidências desses princípios e mostraram que havia sim uma justiça organizada, um sistema jurídico com um funcionamento próprio e um direito complexo, como exemplifica perfeitamente o tratado de Philippe de Beaumanoir.

Com esse breve estudo dos direitos de justiça e de polícia nos Costumes de Beauvaisis e à luz da antropologia jurídica, procuramos entender como se davam as relações de poder entre senhores feudais e seus súditos por intermédio dos direitos fixados nos costumes. A análise dos direitos de justiça e de polícia nos Costumes de Beauvaisis permitiu discernir um pouco das formas de organização social do senhorio e as dinâmicas das relações de poder que caracterizam o tipo de autoridade que é chamada de ban e que se refere não apenas a um poder de comando, mas ao poder de justiça. Os exemplos selecionados revelam a importância que assume o exercício da justiça nos costumes de Beauvaisis. Confirmam a tese de que boa parte da renda senhorial, também em Beauvaisis, advinha desses direitos de justiça e de polícia e que, era graças ao seu exercício de justiça que o senhor podia adquirir o poder necessário para exigir de todos seus súditos os outros direitos.

A obra de Philippe de Beaumanoir evidencia que o senhorio é, antes de tudo, uma porção de terra, porém habitada e, acima de tudo, habitada por súditos. É uma porção de terra onde o senhor, que pode ser proprietário ou não, exerce um direito real de soberania. Aí também, tal como nos ambientes mais elevados de homenagem militar, existiam "homens de outros homens". Nos degraus inferiores, as relações de dependência encontravam seu quadro natural neste grupamento que sobreviveu muito tempo após o declínio da vassalagem: o senhorio. No quadro do senhorio, a obra de Beaumanoir mostra bem as duas formas de sujeição evidenciadas por Marc Bloch: "a que pesava sobre o homem em sua pessoa; a que o atingia somente enquanto detentor de uma porção de terra" (1994, p. 233).

O senhorio assiste, durante o século XIII, a um período de prosperidade econômica, um movimento de modificações em sua organização. Este movimento é acompanhado pela ampliação das necessidades financeiras dos senhores e, em conse- 
quência, pelo aumento da exploração fiscal. Neste momento, é sobretudo o exercício da justiça que permite-lhes prover às suas despesas e aumentar sua fortuna. É nesse quadro que se insere a sistematização conduzida por Beaumanoir, bailio do rei no Condado de Clermont de Beauvaisis situado nos domínios reais.

No que diz respeito à relação entre o poder real e o poder senhorial, muitos historiadores acreditaram ser o século XIII o momento do fortalecimento do poder real em detrimento do enfraquecimento do poder senhorial. O que se percebe com a leitura de Beaumanoir é que, de fato, o rei procurava cada vez mais se impor promulgando ordenanças e enviando oficiais especializados para cuidar dos assuntos jurídicos nos seus domínios. No entanto, os direitos senhoriais ainda se mostram fortes como nos períodos anteriores ao auge do feudalismo. De acordo com Dominique Barthélemy (1990), não se pode falar em um enfraquecimento do senhorial neste período. O autor contesta a tese colocada pela escola mutacionista do ano mil segundo a qual o século XIII seria um período de transição que, do ponto de vista político, se caracterizava pela perda de poder dos senhores feudais e pela imposição do poder real. Ele defende a tese de que o poder senhorial continua forte no século XIII e cresce paralelamente ao poder real (1990, p. 199-252).

Os direitos senhoriais consolidados no coutumier de Beauvaisis retratam um fortalecimento das dependências características do feudalismo; dominação conjugada com as possibilidades de exploração por ela abertas. Uma conclusão apressada seria a de que a consolidação dos costumes elaborada por um funcionário do rei demonstraria o fortalecimento do poder real e, em consequência, do Estado. Contudo, como bem notou Jacques Le Goff, "a monarquia, longe de ser incompatível com a feudalidade, se combina com as estruturas e mentalidades feudais e consolida, assim, sua força" (1996, p. 65).

\section{REFERÊNCIAS}

ANDERSON, Perry. 1982. Passagens da Antiguidade ao Feudalismo, $2^{a}$ edição. Porto, Biblioteca das Ciências do Homem, Edições Afrontamento.

BARTHÉLEMY, Dominique. 1990. L'Ordre Seigneurial (Xlème - Xllème), Collection Nouvelle Histoire de la France Médiévale, vol. 3. Paris, Seuil.

1992. Qu'est-ce que le servage en France au Xlème siècle?, Revue Historique, n. 287.

BASCHET, Jérôme. 2006. A Civilização feudal: do ano mil à colonização da América, São 
Paulo, Editora Globo.

BEAUMANOIR, Philippe de. 1970. Coutumes de Beauvaisis, volumes 1 e 2. Paris, Éditions A. et J. Picard.

BLOCH, Marc. 1994. La société féodale. Paris, Albin Michel.

BOUTRUCHE, Robert. 1970. Seigneurie et Féodalité. L'apogée (Xlème - XIllème). Paris, Aubier.

CHARBONNIER, Pierre. 1995. Essai d'un classement des redevances seigneuriales. In: FOSSIER, Robert, Seigneurs et seigneuries au Moyen Âge. Paris, Éditions du C.T.H.S., pp. 139-151.

CONTAMINE, Philippe. 1995. La seigneurie en France à la fin du Moyen Âge, In: FOSSIER, Robert, Seigneurs et Seigneurie au Moyen Âge. Paris, Éditions du C.T.H.S., pp. $25-43$.

DUBY, Georges. 1977. L'économie rurale et la vie des campagnes dans l'Occident Médiéval, vol. 2. Paris, Champs/Flammarion.

ELIAS, Norbert. 1993. O Processo Civilizador. Formação do Estado e da Civilização, vol. 2. Rio de Janeiro, Jorge Zahar Editor.

ELLUL, Jacques. 2013. Histoire des Institutions. Le Moyen Âge. Paris, PUF.

FOSSIER, Robert. 1995. Seigneurs et Seigneurie au Moyen Âge. Paris, Éditions du C.T.H.S.

HUBRECHT, Georges. 1974. Commentaire historique et juridique. In: Coutumes de Beauvaisis, Tome 3. Paris, Éditions A. et J. Picard.

LE GOFF, Jacques. 1982. Le XIIlème siècle: l'apogée de la chrétienté (vers 1180 - 1330), Paris, Bordas. 1996. Saint Louis. Paris, Gallimard.

LEMARIGNIER, Jean-François. 1970. La France Médiévale. Institutions et Société. Paris, Armand Colin.

LETURCQ, Samuel. 2004. La vie rurale au Moyen Âge: Xe - XVe siècles. Paris, A. Colin. LÉVY-BRUHL, Henri. 1955. Aspects sociologiques du droit. Paris, Librairie Marcel Rivière.

LORCIN, Marie-Thérèse. 1985. Société et cadre de vie en France, Angleterre et Bourgogne (1050 - 1250). Paris, SEDES.

OLIVIER-MARTIN, François. 1992. Histoire du droit français des origines à la Révolution. Paris, Éditions du CNRS.

ROULAND, Norbert. 1990. L'anthropologie juridique. Paris, PUF. 